\title{
Effects of maximum residue limit of triflumezopyrim exposure on fitness of the red imported fire ant Solenopsis invicta
}

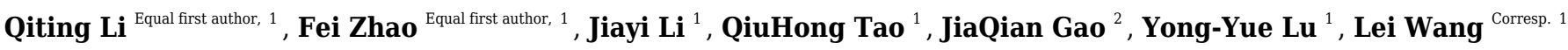 \\ ${ }^{1}$ College of Agriculture, South China Agricultural University, Guangzhou, Guangdong, China \\ 2 Guangdong Tianhe Agricultural Means of Production Co., Ltd., Guangzhou, Guangdong, China \\ Corresponding Author: Lei Wang \\ Email address: wanglei1107@outlook.com
}

The impact of exposure to free feeding concentrations of triflumezopyrim to the red imported fire ant, Solenopsis invicta, in maximum residue tolerances for 56 days was investigated to understand whether triflumezopyrim, a novel neonicotinoid, poses unacceptable risks to the environment. Our results demonstrated that neither $0.5 \mu \mathrm{g} / \mathrm{ml}$ nor $0.2 \mu \mathrm{g} / \mathrm{ml}$ triflumezopyrim have a significant impact on the growth of the $S$. invicta colony and their food consumption (sugar water and locusts) during the length of treatment. Whiles both $0.5 \mu \mathrm{g} / \mathrm{ml}$ and $0.2 \mu \mathrm{g} / \mathrm{ml}$ triflumezopyrim improved the grasping ability of $S$. invicta, and $0.5 \mu \mathrm{g} / \mathrm{ml}$ not $0.2 \mu \mathrm{g} / \mathrm{ml}$ triflumezopyrim increased their rate of locomotion. In addition, although $0.5 \mu \mathrm{g} / \mathrm{ml}$ and $0.2 \mu \mathrm{g} / \mathrm{ml}$ triflumezopyrim increased their individual aggressiveness index, the probability of the survival of $S$. invicta was not impacted by triflumezopyrim treatments in aggressive group encounters. This study suggests that triflumezopyrim did not have a negative impact on the fitness of $S$. invicta at $0.5 \mu \mathrm{g} / \mathrm{ml}$ and $0.2 \mu \mathrm{g} / \mathrm{ml}$ exposures. 


\section{Effects of maximum residue limit of triflumezopyrim}

\section{2 exposure on fitness of the red imported fire ant Solenopsis}

\section{3 invicta}

4

5 Qiting $\mathrm{Li}^{1 *}$, Fei Zhao ${ }^{1 *}$, Jiayi $\mathrm{Li}^{1}$, QiuHong Tao ${ }^{1}$, JiaQian $\mathrm{Gao}^{2}$, Yongyue $\mathrm{Lu}^{1}$, Lei Wang ${ }^{1}$

6

$7{ }^{1}$ College of Agriculture, South China Agricultural University, Guangzhou, Guangdong, China

$8{ }^{2}$ Guangdong Tianhe Agricultural Means of Production Co., Ltd., Guangzhou, Guangdong, China

* Equal contribution by the authors.

12 Corresponding Author:

13 Lei Wang ${ }^{1}$

14483 Wushan Road, Guangzhou, Guangdong, 510642, China

Email address: leiwang@scau.edu.cn

\section{Abstract}

The impact of exposure to free feeding concentrations of triflumezopyrim to the red imported fire ant, Solenopsis invicta, in maximum residue tolerances for 56 days was investigated to understand whether triflumezopyrim, a novel neonicotinoid, poses unacceptable risks to the environment. Our results demonstrated that neither $0.5 \mu \mathrm{g} / \mathrm{ml}$ nor $0.2 \mu \mathrm{g} / \mathrm{ml}$ triflumezopyrim have a significant impact on the growth of the S. invicta colony and their food consumption (sugar water and locusts) during the length of treatment. Whiles both $0.5 \mu \mathrm{g} / \mathrm{ml}$ and $0.2 \mu \mathrm{g} / \mathrm{ml}$ triflumezopyrim improved the grasping ability of $S$. invicta, and $0.5 \mu \mathrm{g} / \mathrm{ml}$ not $0.2 \mu \mathrm{g} / \mathrm{ml}$ triflumezopyrim increased their rate of locomotion. In addition, although $0.5 \mu \mathrm{g} / \mathrm{ml}$ and $0.2 \mu \mathrm{g} / \mathrm{ml}$ triflumezopyrim increased their individual aggressiveness index, the probability of the survival of $S$. invicta was not impacted by triflumezopyrim treatments in aggressive group encounters. This study suggests that triflumezopyrim did not have a negative impact on the fitness of $S$. invicta at $0.5 \mu \mathrm{g} / \mathrm{ml}$ and $0.2 \mu \mathrm{g} / \mathrm{ml}$ exposures.

\section{Introduction}


30 Neonicotinoids are insecticides that act on the nicotinic acetylcholine receptor (nAChR) of insects; it exhibits 31 good activity on sap-sucking pests and comprises over $30 \%$ of insecticide sales in the world (Hladik et al., 32 2018; Ihara \& Matsuda, 2018). However, the negative impact of neonicotinoids on non-target organisms at 33 their sublethal concentrations is of increasing concern (Butcherine et al., 2019; Wang et al., 2018). Research has shown that neonicotinoids have adverse impacts on pollinator insects, especially honeybees, and three types of this chemical are currently banned from the European Union, including imidacloprid, thiamethoxam and clothianidin (Ihara \& Matsuda, 2018; Pisa et al., 2015).

Current, novel neonicotinoids were developed including sulfoxaflor, flupyradifurone, and triflumezopyrim. Researchers have considered the safety of these new neonicotinoids over other neonicotinoids for non-target insects, especially honeybees. Pan et al. (2017) found that $1.0 \mu \mathrm{g} / \mathrm{ml}$ sulfoxaflor reduced aggressiveness, colony growth, and food consumption of the fire ant Solenopsis invicta, while Siviter et al. (2019) found that acute sulfoxaflor exposure did not have negative impacts the olfactory conditioning and working memory of bees. Research showed that flupyradifurone impairs olfactory learning, motor abilities, and the survival of honeybees, including Apis mellifera carnica, A. mellifera ligustica, and A. cerana at even field-realistic doses (Hesselbach \& Scheiner, 2019; Tan et al., 2017; Tosi \& Nieh, 2019).

Triflumezopyrim is developed by DuPont Crop Protection and is effective against sap-sucking pests (Cordova et al., 2016; Zhang, 2017; Zhang et al., 2017). It was registered in China, Korea, and the Philippines in 2016 and Pyraxalt ${ }^{\mathrm{TM}}$ 10\% triflumezopyrim SC, the commercial product, was brought to market in China in 2017 (http://news.agropages.com/News/NewsDetail---19109.htm, access on 2019-6-2; http://www.agroinfo.com.cn/other_detail_4668.html, access on 2019-6-2). Zhu et al. (2018) found that triflumezopyrim is an effective insecticide for suppressing plant hopper populations and is harmless to their natural enemies including Anagrus nilaparvatae, Cyrtorhinus lividipennis, Paederus fuscipes, Pirata subpiraticus, Ummeliata insecticeps, Hylyphantes graminicola, and Pardosa pseudoannulata. Since sulfoxaflor and flupyradifurone were reported to have negative effects on non-target insects, the effects of triflumezopyrim on non-target insects deserves greater attention.

Ants are an important species and a crucial member of their ecosystem; their disruption would negatively impact the health of the ecosystem (Toro et al., 2012). Imidacloprid can change the foraging and competitive behaviors of Lasius niger and L. flavus at sublethal concentrations, which may alter the structure and dynamics of ant communities after oral treatment (Thiel \& Köhler, 2016). $1 \mu \mathrm{g} / \mathrm{ml}$ imidacloprid oral treatment reduced the aggressive behavior of the native ant, Monomorium antarcticum, to the invasive ant, Linepithema humile, which may facilitate a successful invasion by the invasive species (Barbieri et al., 2013). Ants are important predators and terrestrial herbivores with a large amount of soil contact and were exposed to neonicotinoids by oral exposure through plant ingestion as well as by contact exposure through contaminated soil (Hölldobler \& Wilson, 1990).

The red imported fire ant, S. invicta, is a well-studied ant species making it an ideal model on which to study 65 the sublethal effects of neonicotinoids on ants (Vinson, 2013; Wurm et al., 2011). S. invicta is an active and 
66 efficient predator of pests in agroecosystems despite its negative effects on public health, agriculture, and

67 biodiversity (Harvey \& Eubanks, 2004; Vogt et al., 2001; Wang et al., 2016). In this study, we exposed $S$.

68 invicta colonies to residue limits of triflumezopyrim and evaluated the impact of exposure on their fitness. The

69 objective of the study was to determine the effects of the maximum residue limit of triflumezopyrim on the

70 fitness of the colony and the behavior of workers.

\section{Materials \& Methods}

\section{Insects and insecticide}

73 Red imported fire ants, Solenopsis invicta, were collected from an organic farm in Conghua County,

74 Guangzhou, China and reared at the Red Imported Fire Ant Research Centre at the South China Agricultural

75 University. S. invicta colonies were provided with a 10\% w/w sugar water solution and frozen locusts Locusta

76 migratoria. The social form of $S$. invicta colonies were determined using methods of Shoemaker \& Ascunce

77 (2010), and only polygyne colonies were used in this experiment. All bioassays were conducted under

78

79

80

81 laboratory conditions, and all colonies were reared in the laboratory at least 1 week prior to the start of the experiment.

The commercially available insecticide, Pyraxalt ${ }^{\mathrm{TM}}$ 10\% triflumezopyrim SC (DuPontTM Crop Protection, Shanghai, China), was used in all experiments.

\section{Effect of triflumezopyrim on $\boldsymbol{S}$. invicta food consumption and colony growth}

The Environmental Protection Agency (EPA) of the United States establishes tolerances for the residues of triflumezopyrim in rice grains and rice hulls of $0.4 \mathrm{ppm}$ and $1.0 \mathrm{ppm}$, respectively (https://www.federalregister.gov/documents/2017/10/16/2017-22356/triflumezopyrim-pesticide-tolerances, accessed on 2019-6-4). Therefore, we used 0.5 and $0.2 \mu \mathrm{g}$ triflumezopyrim $/ \mathrm{ml}$ for the residue tolerances of triflumezopyrim based on the regulatory requirements of the EPA.

Pyraxalt ${ }^{\mathrm{TM}}$ is advertised to provide up to 25 days of consistent hopper control (http://www.dupont.com/products-and-services/crop-protection/pyraxalt-insect-control.html, access on 2019-62). The estimated average life span of minor, medium, and major workers of $S$. invicta is 45 days, 75 days, and 135 days, respectively (Calabi \& Porter, 1989). In light of these two combined factors the experiment was conducted over 8 weeks.

The experimental method was reflective of the work of Pan et al. (2017) in which a colony was divided into the same weight $(>20 \mathrm{~g})$, and each subcolony contained workers, brood, larva, pupa, and at least one functional queen. Each subcolony then received either the control 10\% w/w sugar water or a single concentration of triflumezopyrim $(0.2$ or $0.5 \mu \mathrm{g} / \mathrm{ml})$ in $10 \% \mathrm{w} / \mathrm{w}$ sugar water; solutions were provided in a $15 \mathrm{ml}$ glass tubes with a cotton stopple. Subcolonies received a sufficient amount of locusts. The weight of each subcolony was taken every 7 days to evaluate the effect of triflumezopyrim on colony growth of $S$. invicta. The accumulated percentage weight loss of each subcolony was calculated after 7, 14, 21, 28, 35, 42, 49, and 56 days of treatment (Pan et al., 2017). Sugar water and locust consumption (mg sugar water or locust per g ant) was also 
101 calculated for each subcolony at $1,7,14,21,28,35,42,49$, and 56 days. Water evaporation was also

102 estimated. Four colonies were used in this experiment.

103 The effect of triflumezopyrim on active behavior of $\boldsymbol{S}$. invicta

104 We evaluated the effect of triflumezopyrim on S. invicta behavior by measuring their grasping ability and

105 walking speed after 56 days of treatment. The experiment method was reflective of the method used by Huang 106 et al. (2016) and Wang et al. (2015).

107 To test the grasping ability of the fire ant, 10 workers varying in size from the treatment or control

108 subcolony were placed on an A4-sized paper. The paper was gently turned over 180 degrees after 10s and held 109 in place for 10s. Workers falling from the paper was considered to have lost their grasping ability. The

110 grasping ability was evaluated by grasping rate using the following formula: grasping rate $(\%)=($ number of

111 workers possessing grasping ability/total number of workers in test) $\times 100 \%$. Each subcolony from each

112 treatment and control group was tested 3 times.

113 To test the walking speed of the fire ants, a tray with a fire ant subcolony was connected to a forging arena

114 (tray, $\mathrm{L} \times \mathrm{W} \times \mathrm{H}, 41.75 \times 27.5 \times 12 \mathrm{~cm}$ ) by a wood bridge. The bridge consists of two $20 \mathrm{~cm}$ vertical segments and 115 one $20 \mathrm{~cm}$ horizontal segment. The walking speed of the workers was measured by recording the time needed

116 for an ant to walk across the $20 \mathrm{~cm}$ horizontal segment of the bridge. The method was described by Wang et al.

117 (2015). A total of 25 workers were measured from each subcolony.

118 The effect of triflumezopyrim on the aggressiveness of $\boldsymbol{S}$. invicta

119 In this experiment, we assessed the effect of sublethal doses of triflumezopyrim on the aggressive behavior of

120 S. invicta. The experimental method was reflective of the method used by Pan et al. (2017). The aggressiveness

121 level of $S$. invicta was assessed when $S$. invicta individuals and colonies were confronted with another ant

122 species, Pheidole fervida, at 56 days after treatment. Four P. fervida colonies were used.

123 S. invicta and P. fervida colonies were paired in interspecific individual or colony interaction tests. The

124 interspecific interaction was quantified using a behavioral assay described by Pan et al. (2017).

125 In interspecific individual aggression, interactions were scored and calculated as described by Rice and

126 Silverman (2013) and Pan et al. (2017). Four replicate experiments were performed for three pairs of colonies

127 with each receiving a dose of triflumezopyrim. Each replicate involved different workers.

128 Interspecific colony aggression was evaluated using an assay described by Pan et al. (2017). Specially, thirty

129 workers varying in size from pairs of treated $S$. invicta and untreated $P$. fervida colonies were randomly chosen

130 and introduced into a petri dish. Mortality rates of $S$. invicta were recorded after $3 \mathrm{~h}$. Three replicates were

131 performed for three pairs of colonies receiving a dose of triflumezopyrim at the same time. Each replicate

132 involved different workers.

133 Statistical analyses

134 All data were analyzed using Shapiro-Wilk and Levene's tests for normal distribution and homogeneity of 135 variances, respectively. If data were normally distributed and had similar variances, then the means of 136 measured variables were compared by one-way analysis of variance (ANOVA). Significant ANOVA results

Peer] reviewing PDF | (2019:07:39149:2:0:NEW 11 Nov 2019) 
137 were corrected for multiple comparisons using LSD's method. Non-normally distributed data were analyzed

138 using a nonparametric Kruskal-Wallis test to compare medians; differences significant at the 0.05 significance 139 level were subjected to a Mann-Whitney test for pairwise comparisons. All statistical analyses were performed 140 using SPSS version 18.0 (SPSS Inc., Chicago, IL, USA).

\section{Results}

\section{Effect of triflumezopyrim on $\boldsymbol{S}$. invicta colony growth}

143 There is no significant difference in the survival of $S$. invicta colonies among $0.5 \mu \mathrm{g} / \mathrm{ml}$ triflumezopyrim,

$1440.2 \mu \mathrm{g} / \mathrm{ml}$ triflumezopyrim, and the control (Fig. 1; day 7, LSD test, $\mathrm{F}_{2,9}=0.404, \mathrm{P}=0.679$; day 14, LSD

145 test, $\mathrm{F}_{2,9}=0.009, \mathrm{P}=0.991$; day 21 , LSD test, $\mathrm{F}_{2,9}=0.116, \mathrm{P}=0.892$; day 28 , LSD test, $\mathrm{F}_{2,9}=0.089, \mathrm{P}=0.916$;

146 day $35, \mathrm{LSD}$ test, $\mathrm{F}_{2,9}=0.298, \mathrm{P}=0.749$; day 42, $\mathrm{LSD}$ test, $\mathrm{F}_{2,9}=0.746, \mathrm{P}=0.501$; day 49, LSD test,

$147 \mathrm{~F}_{2,9}=0.488, \mathrm{P}=0.629$; day $56, \mathrm{LSD}$ test, $\left.\mathrm{F}_{2,9}=0.527, \mathrm{P}=0.608\right)$. After 56 days of treatment, the accumulated 148 percentage weight losses were $51.40 \%, 50.65 \%$, and $58.46 \%$ in colonies treated with $0.5 \mu \mathrm{g} / \mathrm{ml}$

149 triflumezopyrim, $0.2 \mu \mathrm{g} / \mathrm{ml}$ triflumezopyrim, and controls, respectively.

\section{Effect of triflumezopyrim on $\boldsymbol{S}$. invicta food consumption}

151 There is no significant difference in sugar consumption between ants treated with $0.5 \mu \mathrm{g} / \mathrm{ml}$

152 triflumezopyrim, $0.2 \mu \mathrm{g} / \mathrm{ml}$ triflumezopyrim, and the control (Table 1; day 1, LSD test, $\mathrm{F}_{2,9}=0.946$,

$153 \mathrm{P}=0.418$; day 7, LSD test, $\mathrm{F}_{2,9}=0.673, \mathrm{P}=0.534$; day 14 , LSD test, $\mathrm{F}_{2,9}=0.322, \mathrm{P}=0.733$; day 21, LSD test, $154 \mathrm{~F}_{2,9}=1.396, \mathrm{P}=0.296$; day 28 , LSD test, $\mathrm{F}_{2,9}=2.129, \mathrm{P}=0.175$; day 35 , $\mathrm{LSD}$ test, $\mathrm{F}_{2,9}=0.283, \mathrm{P}=0.760$; day 15542 , LSD test, $\mathrm{F}_{2,9}=1.472, \mathrm{P}=0.280$; day 49, LSD test, $\mathrm{F}_{2,9}=1.768, \mathrm{P}=0.225$; day $56, \mathrm{LSD}$ test, $\mathrm{F}_{2,9}=0.782$, $156 \mathrm{P}=0.486)$.

157 Triflumezopyrim treatments do not have an impact on locust consumption (Table 2; day 1, LSD test, $158 \mathrm{~F}_{2,9}=0.004, \mathrm{P}=0.996$; day 7 , LSD test, $\mathrm{F}_{2,9}=0.172, \mathrm{P}=0.845$; day 14 , LSD test, $\mathrm{F}_{2,9}=0.539, \mathrm{P}=0.601$; day 15921 , LSD test, $\mathrm{F}_{2,9}=1.726, \mathrm{P}=0.232$; day 28, LSD test, $\mathrm{F}_{2,9}=1.443, \mathrm{P}=0.286$; day 35, LSD test, $\mathrm{F}_{2,9}=3.691$, $160 \mathrm{P}=0.068$; day 42, LSD test, $\mathrm{F}_{2,9}=0.728, \mathrm{P}=0.509$; day 49, LSD test, $\mathrm{F}_{2,9}=1.940, \mathrm{P}=0.199$; day 56, LSD test, $\left.161 \mathrm{~F}_{2,9}=0.089, \mathrm{P}=0.915\right)$.

\section{Effect of triflumezopyrim on S. invicta activity behavior}

163 After 56 days of treatment the grasping rate of workers was $88.67 \pm 2.14 \%, 90.33 \pm 1.67 \%$, and

$16471.67 \pm 5.13 \%$ in $0.5 \mu \mathrm{g} / \mathrm{ml}$ triflumezopyrim, $0.2 \mu \mathrm{g} / \mathrm{ml}$ triflumezopyrim, and the control, respectively. The 165 grasping rate of workers in the triflumezopyrim treatment is higher than that of the control $(0.5 \mu \mathrm{g} / \mathrm{ml}$ 166 triflumezopyrim and control, Mann-Whitney test, $\mathrm{U}=27, \mathrm{P}=0.009 ; 0.2 \mu \mathrm{g} / \mathrm{ml}$ triflumezopyrim and control, 167 Mann-Whitney test, $\mathrm{U}=18, \mathrm{P}=0.002$ ).

168 After 56 days of treatment the walking speed of workers was $9.50 \pm 0.22 \mathrm{~mm} / \mathrm{s}, 9.39 \pm 0.23 \mathrm{~mm} / \mathrm{s}$, and $1699.41 \pm 0.38 \mathrm{~mm} / \mathrm{s}$ in $0.5 \mu \mathrm{g} / \mathrm{ml}$ triflumezopyrim, $0.2 \mu \mathrm{g} / \mathrm{ml}$ triflumezopyrim, and control, respectively. The 170 walking speed of workers in $0.5 \mu \mathrm{g} / \mathrm{ml}$ triflumezopyrim treatment was higher than that of the control $(0.5$ 
$171 \mu \mathrm{g} / \mathrm{ml}$ triflumezopyrim and control, Mann-Whitney test, $\mathrm{U}=4044.5, \mathrm{P}=0.02$ ), and the walking speed of

172 workers in the $0.2 \mu \mathrm{g} / \mathrm{ml}$ triflumezopyrim treatment is not significantly different from either that in the 0.5

$173 \mu \mathrm{g} / \mathrm{ml}$ triflumezopyrim or the control $(0.2 \mu \mathrm{g} / \mathrm{ml}$ triflumezopyrim and control, Mann-Whitney test,

$174 \mathrm{U}=4199.5, \mathrm{P}=0.050 ; 0.2 \mu \mathrm{g} / \mathrm{ml}$ triflumezopyrim and $0.5 \mu \mathrm{g} / \mathrm{ml}$ triflumezopyrim, Mann-Whitney test,

$175 \mathrm{U}=4733.0, \mathrm{P}=0.514)$.

\section{Effect of triflumezopyrim on $\boldsymbol{S}$. invicta aggressiveness}

177 After 56 days of treatment the aggressiveness indices of $S$. invicta workers was $1.58 \pm 0.28,1.31 \pm 0.29$, and

$1780.47 \pm 0.20$ in $0.5 \mu \mathrm{g} / \mathrm{ml}$ triflumezopyrim, $0.2 \mu \mathrm{g} / \mathrm{ml}$ triflumezopyrim, and the control, respectively. The

179 aggressiveness index of $S$. invicta was significantly increased by triflumezopyrim treatment $(0.5 \mu \mathrm{g} / \mathrm{ml}$

180 triflumezopyrim and control, Mann-Whitney test, $\mathrm{U}=57.5, \mathrm{P}=0.004 ; 0.2 \mu \mathrm{g} / \mathrm{ml}$ triflumezopyrim and

181 control, Mann-Whitney test, $\mathrm{U}=75.5, \mathrm{P}=0.030$ ).

182 In the group aggression experiment, the mortality of $S$. invicta workers was $6.33 \pm 1.51 \%, 6.67 \pm 1.80 \%$,

$1837.33 \pm 2.14 \%$ in $0.5 \mu \mathrm{g} / \mathrm{ml}$ triflumezopyrim, $0.2 \mu \mathrm{g} / \mathrm{ml}$ triflumezopyrim, and control after 56 days of

184 treatment, respectively; there is no significant difference among triflumezopyrim treatments and the

185 control (LSD test, $\left.\mathrm{F}_{2,33}=0.77, \mathrm{P}=0.926\right)$.

\section{Discussion}

187 The negative impact of neonicotinoids on non-target organisms is a global concern. As a novel

188 neonicotinoid, the impact of triflumezopyrim on non-target insects deserves attention. Zhu et al. (2017)

189 found that $62.5 \mu \mathrm{g}$ a.i $/ \mathrm{ml}$ triflumezopyrim does not negatively impact the parasitic wasp Anagrus

190 nilaparvatae after $30 \mathrm{~min}$ of exposure. Our study showed that 0.2 and $0.5 \mu \mathrm{g} / \mathrm{ml}$ triflumezopyrim, which

191 are near the tolerance levels for the residue of triflumezopyrim in rice grains and hulls, does not have a

192 negative effect on the colony growth and food consumption (sugar water and locusts) of fire ants after 56

193 day of exposure. Although the 0.2 and $0.5 \mu \mathrm{g} / \mathrm{ml}$ triflumezopyrim treatments increased the grasping

194 ability and individual aggressiveness of fire ant workers, and $0.5 \mu \mathrm{g} / \mathrm{ml}$ triflumezopyrim treatment

195 increased the walking speed of fire ants, triflumezopyrim treatment did not impact the mortality of fire ant

196 workers in the group aggression experiment.

197 Rondeau et al. (2014) suggested that testing for the chronic effects of pesticides should be extended to

19830 days or more for social insects. The estimated average life span of minor, medium, and major workers

199 is 45 days, 75 days, and 135 days, respectively (Calabi \& Porter, 1989). Our experiments were conducted

200 for 56 days in light of the abovementioned factors. We used three experimental parameters to investigate

201 the impact of tolerances for the residues of triflumezopyrim exposure on fire ant colony growth, food

202 consumption, and activity. The three parameters were chosen because they are related to the fitness of the

203 fire ant colony. For example, walking speed and aggressiveness is involved in competition for food, and

204 the protection and expansion of territory, which are indicators of competitiveness in ants (Holway, 1999). 
205 Our results showed that the treatments of 0.2 and $0.5 \mu \mathrm{g} / \mathrm{ml}$ triflumezopyrim increased the grasping 206 ability and aggressiveness of the individual worker and $0.5 \mu \mathrm{g} / \mathrm{ml}$ triflumezopyrim increased the walking 207 speed of the fire ant. Other neonicotinoids have a similar effect. For example, thiamethoxam at $108.1 \mathrm{ng} / \mathrm{g}$ 208 exposure caused a short-term locomotor hyperactivity of the carabid beetle Platynus assimilis (Tooming 209 et al., 2017). The lower concentration of imidacloprid, such as $10 \mathrm{ng}$ or $1.25 \mathrm{ng} / \mathrm{insect}$ treatment, resulted 210 in a higher locomotor activity of the treated insect (Galvanho et al., 2013; Lambin et al., 2010). França et 211 al. (2017) indicated that insect behavior changes with sublethal doses of pesticides, which may indirectly 212 influence species biology and fitness. However, behavior changes resulting in fire ant fitness for colony 213 growth and group aggression was not impacted based on our data.

214 Registration information of triflumezopyrim is submitted to many key markets of the world and is now 215 registered for sale in China (http://news.agropages.com/News/NewsDetail---19109.htm). Our study

216 revealed that there is no negative impact of $0.5 \mu \mathrm{g} / \mathrm{ml}$ triflumezopyrim exposure on the colony growth and 217 food consumption of the fire ant. Further studies are needed to determine the conditions under which 218 triflumezopyrim may have a detrimental impact on ants. Our results provide information for the future use 219 of this insecticide on crops in terms of regulations and policy decisions.

\section{Conclusions}

221 We found triflumezopyrim, a novel neonicotinoid, did not cause any negative impact on the fitness of the 222 fire ant $S$. invicta at 0.2 and $0.5 \mu \mathrm{g} / \mathrm{ml}$ after 56 days of observation. Neither colony growth nor food 223 consumption was influenced by 0.2 and $0.5 \mu \mathrm{g} / \mathrm{ml}$ triflumezopyrim. The probability of survival of $S$.

224 invicta was not impacted by triflumezopyrim treatments in aggressive group encounters, although 0.5

$225 \mu \mathrm{g} / \mathrm{ml}$ and $0.2 \mu \mathrm{g} / \mathrm{ml}$ triflumezopyrim increased the individual aggressive index, and $0.5 \mu \mathrm{g} / \mathrm{ml}$

226 triflumezopyrim increased the moving speed and grasping ability of $S$. invicta. The results imply that the 227 maximum residue limit of triflumezopyrim may have no impact on other non-target ants.

\section{Acknowledgements}

229 We thank Jiefu Deng and Dong Ning for their valuable help in the experimental setup. We also 230 thank the editor and reviewers for their constructive comments on this paper.

\section{References}

232 Barbieri RF, Lester PJ, Miller AS \& Ryan KG (2013) A neurotoxic pesticide changes the 233 outcome of aggressive interactions between native and invasive ants. Proceedings of the Royal 234 Society B-Biological Sciences 280: 7. doi:10.1098/rspb.2013.2157.

235 Butcherine P, Benkendorff K, Kelaher B \& Barkla BJ (2019) The risk of neonicotinoid exposure 236 to shrimp aquaculture. Chemosphere 217: 329-348. doi:10.1016/j.chemosphere.2018.10.197. 
237 Calabi P \& Porter SD (1989) Worker longevity in the fire ant Solenopsis invicta: Ergonomic 238 considerations of correlations between temperature, size and metabolic rates. Journal of Insect 239 Physiology 35: 643-649.

240 Cordova D, Benner EA, Schroeder ME, Holyoke CW, Zhang W, Pahutski TF, Leighty RM, 241 Vincent DR \& Hamm JC (2016) Mode of action of triflumezopyrim: A novel mesoionic 242 insecticide which inhibits the nicotinic acetylcholine receptor. Insect Biochemistry and 243 Molecular Biology 74: 32-41. doi:10.1016/j.ibmb.2016.04.008.

244 França SMd, Breda MO, Barbosa DRS, Araujo AMN \& Guedes CA (2017) The sublethal effects 245 of insecticides in insects: Biological Control of Pest and Vector Insects (ed. by VDC Shields) 246 IntechOpen, London, United Kingdom.

247 Galvanho JP, Carrera MP, Moreira DDO, Erthal M, Silva CP \& Samuels RI (2013) Imidacloprid 248 inhibits behavioral defences of the leaf-cutting ant Acromyrmex subterraneus subterraneus 249 (Hymenoptera: Formicidae). Journal of Insect Behavior 26: 1-13. doi:10.1007/s 10905-012-93282506.

251 Harvey CT \& Eubanks MD (2004) Effect of habitat complexity on biological control by the red 252 imported fire ant (Hymenoptera: Formicidae) in collards. Biological Control 29: 348-358. 253 Hesselbach H \& Scheiner R (2019) The novel pesticide flupyradifurone (Sivanto) affects 254 honeybee motor abilities. Ecotoxicology 28: 354-366. doi:10.1007/s10646-019-02028-y. 255 Hladik ML, Main AR \& Goulson D (2018) Environmental risks and challenges associated with 256 neonicotinoid insecticides. Environmental Science \& Technology 52: 3329-3335. 257 doi:10.1021/acs.est.7b06388.

258 Hölldobler B \& Wilson EO (1990) The ants. Harvard University Press, Cambridge, MA. 259 Holway DA (1999) Competitive mechanisms underlying the displacement of native ants by the 260 invasive argentine ant. Ecology 80: 238-251.

261 Huang SQ, Fu JT, Wang K, Xu HH \& Zhang ZX (2016) Insecticidal activity of the methanol 262 extract of Pronephrium megacuspe (Thelypteridaceae) and its active component on Solenopsis 263 invicta (Hymenoptera: Formicidae). Florida Entomologist 99: 634-638.

264 doi:https://doi.org/10.1653/024.099.0408.

265 Ihara M \& Matsuda K (2018) Neonicotinoids: molecular mechanisms of action, insights into 266 resistance and impact on pollinators. Current Opinion in Insect Science 30: 86-92. 267 doi:10.1016/j.cois.2018.09.009. 
268 Lambin M, Armengaud C, Raymond S \& Gauthier M (2010) Imidacloprid-induced facilitation of

269 the proboscis extension reflex habituation in the honeybee. Arch Insect Biochem Physiol 48:

270 129-134.

271 Pan FX, Lu YY \& Wang L (2017) Toxicity and sublethal effects of sulfoxaflor on the red 272 imported fire ant, Solenopsis invicta. Ecotoxicology and Environmental Safety 139: 377-383. 273 doi:10.1016/j.ecoenv.2017.02.014.

274 Pisa LW, Amaral-Rogers V, Belzunces LP, Bonmatin JM, Downs CA, Goulson D, Kreutzweiser 275 DP, Krupke C, Liess M \& Mcfield M (2015) Effects of neonicotinoids and fipronil on non-target 276 invertebrates. Environmental Science \& Pollution Research International 22: 68-102.

277 Qi G, Huang Y, Cen Y \& Lu L (2015) Effects of the red imported fire ant, Solenopsis invicta 278 Buren, on the structure and diversity of the ant community in a human disturbed area. Chinese 279 Journal of Applied Entomology 52: 1368-1375.

280 Rice ES \& Silverman J (2013) Submissive behaviour and habituation facilitate entry into habitat 281 occupied by an invasive ant. Animal Behaviour 86: 497-506.

282 Rondeau G, Sánchezbayo F, Tennekes HA, Decourtye A, Ramírezromero R \& Desneux N 283 (2014) Delayed and time-cumulative toxicity of imidacloprid in bees, ants and termites.

284 Scientific Reports 4: 5566.

285 Shoemaker D \& Ascunce MS (2010) A new method for distinguishing colony social forms of the 286 fire ant, Solenopsis invicta. Journal of Insect Science 10: 73. doi:10.1673/031.010.7301.

287 Siviter H, Scott A, Pasquier G, Pull CD, Brown MJF \& Leadbeater E (2019) No evidence for 288 negative impacts of acute sulfoxaflor exposure on bee olfactory conditioning or working 289 memory. PeerJ 7: e7208. doi:https://doi.org/10.7717/peerj.7208.

290 Tan K, Wang C, Dong SH, Li XY \& Nieh JC (2017) The pesticide flupyradifurone impairs 291 olfactory learning in Asian honey bees (Apis cerana) exposed as larvae or as adults. Scientific 292 Reports 7: 9. doi:10.1038/s41598-017-18060-z.

293 Thiel S \& Köhler HR (2016) A sublethal imidacloprid concentration alters foraging and 294 competition behaviour of ants. Ecotoxicology 25: 814-823.

295 Tooming E, Merivee E, Must A, Merivee MI, Sibul I, Nurme K \& Williams IH (2017) 296 Behavioural effects of the neonicotinoid insecticide thiamethoxam on the predatory insect 297 Platynus assimilis. Ecotoxicology 26: 902-913. doi:10.1007/s10646-017-1820-5. 
298 Toro ID, Ribbons RR \& Pelini SL (2012) The little things that run the world revisited: a review 299 of ant-mediated ecosystem services and disservices (Hymenoptera: Formicidae).

300 Myrmecological News 17: 133-146.

301 Tosi S \& Nieh JC (2019) Lethal and sublethal synergistic effects of a new systemic pesticide, 302 flupyradifurone (Sivanto (R)), on honeybees. Proceedings of the Royal Society B-Biological 303 Sciences 286: 9. doi:10.1098/rspb.2019.0433.

304 Vinson SB (2013) Impact of the invasion of the imported fire ant. Insect Science 20: 439-455. 305 doi:10.1111/j.1744-7917.2012.01572.x.

306 Vogt JT, Grantham RA, Smith WA \& Arnold DC (2001) Prey of the red imported fire ant 307 (Hymenoptera: Formicidae) in Oklahoma peanuts. Environmental Entomology 30: 123-128. 308 doi:10.1603/0046-225x-30.1.123.

309 Wang L, Wang Z, Zeng L \& Lu YY (2016) Red imported fire ant invasion reduced the 310 populations of two banana insect pests in south China. Sociobiology 63: 889-893.

311 Wang L, Zeng L \& Chen J (2015) Sublethal effect of imidacloprid on Solenopsis invicta 312 (Hymenoptera: Formicidae) feeding, digging, and foraging behavior. Environmental Entomology 313 44: 1544-1552.

314 Wang X, Anadon A, Wu QH, Qiao F, Ares I, Martinez-Larranaga MR, Yuan ZH \& Martinez 315 MA (2018) Mechanism of neonicotinoid toxicity: Impact on oxidative stress and metabolism. 316 Annual Review of Pharmacology and Toxicology 58: 471-507.

317 Wurm Y, Wang J, Riba-Grognuz O, Corona M, Nygaard S, Hunt BG, Ingram KK, Falquet L, 318 Nipitwattanaphon M, Gotzek D, Dijkstra MB, Oettler J, Comtesse F, Shih CJ, Wu WJ, Yang CC, 319 Thomas J, Beaudoing E, Pradervand S, Flegel V, Cook ED, Fabbretti R, Stockinger H, Long L, 320 Farmerie WG, Oakey J, Boomsma JJ, Pamilo P, Yi SV, Heinze J, Goodisman MAD, Farinelli L, 321 Harshman K, Hulo N, Cerutti L, Xenarios I, Shoemaker D \& Keller L (2011) The genome of the 322 fire ant Solenopsis invicta. Proceedings of the National Academy of Sciences of the United 323 States of America 108: 5679-5684. doi:10.1073/pnas.1009690108.

324 Zhang WM (2017) Mesoionic pyrido 1,2-a pyrimidinone Insecticides: From discovery to 325 triflumezopyrim and dicloromezotiaz. Accounts of Chemical Research 50: 2381-2388. 326 doi:10.1021/acs.accounts.7b00311.

327 Zhang WM, Holyoke CW, Pahutski TF, Lahm GP, Barry JD, Cordova D, Leighty RM, Singh V, 328 Vicent DR, Tong MHT, Hughes KA, McCann SF, Henry YT, Xu M \& Briddell TA (2017) 
329 Mesoionic pyrido 1,2-a pyrimidinones: Discovery of triflumezopyrim as a potent hopper

330 insecticide. Bioorganic \& Medicinal Chemistry Letters 27: 16-20.

331 doi:10.1016/j.bmcl.2016.11.042.

332 Zhu J, Li Y, Jiang H, Liu C, Lu WW, Dai W, Xu JX \& Liu F (2018) Selective toxicity of the 333 mesoionic insecticide, triflumezopyrim, to rice planthoppers and beneficial arthropods.

334 Ecotoxicology 27: 411-419. doi:10.1007/s10646-018-1904-X.

335

336

337

338

339

340

341

342

343

344

345

346

347

348

349

350

351

352

353

354

355

356

357

358

359 
Figure 1

Fig. 1 Accumulated colony weight loss (mean percentage \pm SE) over 56 days after treatment of Solenopsis invicta with different concentrations of triflumezopyrim.

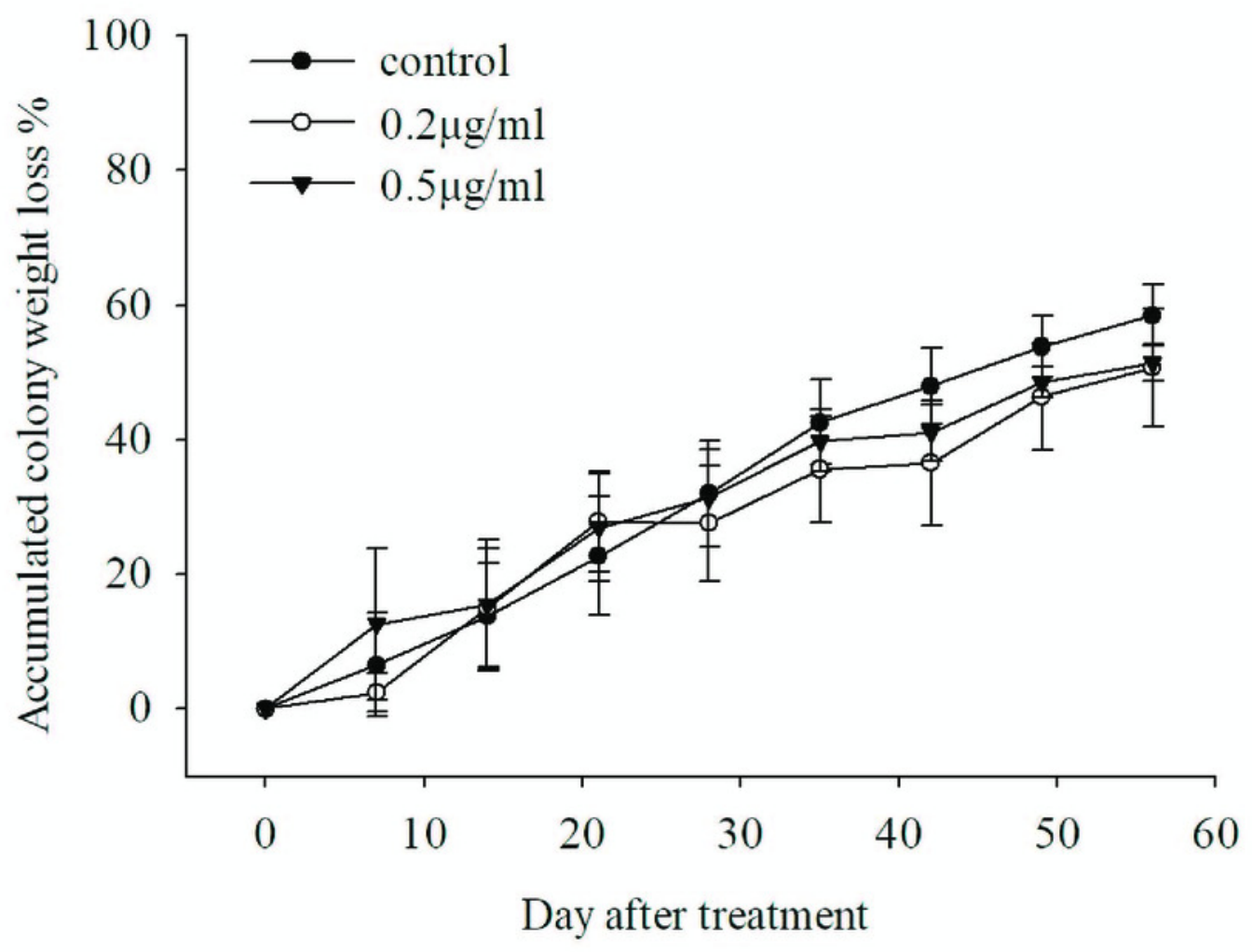




\section{Table 1 (on next page)}

Table 1 Sugar water consumption (mean \pm SE) after 56 days treatment (number of colonies/treatment group $=4$ ). 
1 Table 1 Sugar water consumption (mean $\pm \mathrm{SE}$ ) after 56 days treatment (number of colonies/treatment

2 group =4).

\begin{tabular}{|c|c|c|c|c|c|}
\hline \multirow{2}{*}{$\begin{array}{l}\text { Day after } \\
\text { treatment }\end{array}$} & \multicolumn{3}{|c|}{ sugar water consumption (mg per gram workers) } & \multicolumn{2}{|c|}{ Results of the one-way ANOVA } \\
\hline & Control & $0.2 \mu \mathrm{g} / \mathrm{ml}$ & $0.5 \mu \mathrm{g} / \mathrm{ml}$ & $\mathrm{F}_{2,9}$ & $\mathrm{P}$ \\
\hline 1 & $149.7 \pm 37.3 \mathrm{a}$ & $214.6 \pm 36.8 \mathrm{a}$ & $195.5 \pm 26.9 \mathrm{a}$ & 0.946 & 0.418 \\
\hline 7 & $145.4 \pm 29.4 \mathrm{a}$ & $120.5 \pm 25.6 \mathrm{a}$ & $102.6 \pm 23.2 \mathrm{a}$ & 0.673 & 0.534 \\
\hline 14 & $139.7 \pm 11.5 \mathrm{a}$ & $152.1 \pm 25.3 \mathrm{a}$ & $130.8 \pm 17.2 \mathrm{a}$ & 0.322 & 0.733 \\
\hline 21 & $153.5 \pm 41.2 \mathrm{a}$ & $185.7 \pm 19.0 \mathrm{a}$ & $112.6 \pm 28.7 \mathrm{a}$ & 1.396 & 0.296 \\
\hline 28 & $135.8 \pm 30.7 \mathrm{a}$ & $77.0 \pm 12.9 \mathrm{a}$ & $96.9 \pm 12.3 \mathrm{a}$ & 2.129 & 0.175 \\
\hline 35 & $145.9 \pm 17.3 \mathrm{a}$ & $129.4 \pm 22.3 \mathrm{a}$ & $154.8 \pm 31.0 \mathrm{a}$ & 0.283 & 0.760 \\
\hline 42 & $95.9 \pm 16.7 \mathrm{a}$ & $66.4 \pm 7.9 \mathrm{a}$ & $90.1 \pm 12.5 \mathrm{a}$ & 1.472 & 0.280 \\
\hline 49 & $84.5 \pm 8.4 \mathrm{a}$ & $139.8 \pm 34.8 \mathrm{a}$ & $100.8 \pm 9.5 \mathrm{a}$ & 1.768 & 0.225 \\
\hline 56 & $81.2 \pm 10.8 \mathrm{a}$ & $99.8 \pm 11.9 \mathrm{a}$ & $98.3 \pm 12.2 \mathrm{a}$ & 0.782 & 0.486 \\
\hline
\end{tabular}

3 Notice: Same letter represents no significant difference within each observation period $(\mathrm{P}>0.05)$.

4

5 


\section{Table 2 (on next page)}

Table 2 Locust consumption (mean $\pm \mathrm{SE}$ ) after 56 days treatment (number of colonies/treatment group $=4$ ). 
1 Table 2 Locust consumption (mean \pm SE) after 56 days treatment (number of colonies/treatment group =4).

\begin{tabular}{lllllll}
\hline \multirow{2}{*}{$\begin{array}{l}\text { Day after } \\
\text { treatment }\end{array}$} & \multicolumn{2}{l}{ sugar water consumption $(\mathrm{mg}$ per gram workers) } & & \multicolumn{2}{l}{ Results of the one-way ANOVA } \\
\cline { 2 - 3 } & Control & $0.2 \mu \mathrm{g} / \mathrm{ml}$ & $0.5 \mu \mathrm{g} / \mathrm{ml}$ & & $\mathrm{F}_{2,9}$ & $\mathrm{P}$ \\
7 & $71.4 \pm 47.0 \mathrm{a}$ & $76.5 \pm 33.3 \mathrm{a}$ & $72.6 \pm 47.6 \mathrm{a}$ & & 0.004 & 0.996 \\
14 & $33.5 \pm 33.4 \mathrm{a}$ & $41.9 \pm 18.6 \mathrm{a}$ & $20.0 \pm 26.1 \mathrm{a}$ & & 0.172 & 0.845 \\
21 & $17.5 \pm 13.9 \mathrm{a}$ & $38.0 \pm 16.8 \mathrm{a}$ & $30.3 \pm 10.9 \mathrm{a}$ & & 0.539 & 0.601 \\
28 & $30.6 \pm 8.4 \mathrm{a}$ & $63.6 \pm 20.2 \mathrm{a}$ & $67.1 \pm 15.1 \mathrm{a}$ & & 1.726 & 0.232 \\
35 & $23.8 \pm 7.5 \mathrm{a}$ & $33.9 \pm 5.9 \mathrm{a}$ & $15.0 \pm 9.8 \mathrm{a}$ & & 1.443 & 0.286 \\
42 & $39.6 \pm 16.6 \mathrm{a}$ & $67.8 \pm 18.0 \mathrm{a}$ & $102.8 \pm 14.5 \mathrm{a}$ & & 3.691 & 0.068 \\
49 & $-15.1 \pm 19.9 \mathrm{a}$ & $10.3 \pm 23.1 \mathrm{a}$ & $22.4 \pm 24.1 \mathrm{a}$ & & 0.728 & 0.509 \\
56 & $-1.6 \pm 12.1 \mathrm{a}$ & $49.6 \pm 29.1 \mathrm{a}$ & $61.6 \pm 27.3 \mathrm{a}$ & & 1.940 & 0.199 \\
\hline
\end{tabular}

2 Notice: Same letter represents no significant difference within each observation period $(\mathrm{P}>0.05)$. 